\title{
Waktu dan Cara Aplikasi Cendawan Mikoriza Arbuskular (CMA) pada Pertumbuhan Bibit Tanaman Kopi
}

\section{The Time and Applications Method of Vesicular Arbuscular Mycorrhizae (VAM) on Growth of Coffee Seedlings}

\section{Yonathan Parapasan dan Adryade Reshi Gusta}

Jurusan Budidaya Tanaman Perkebunan Politeknik Negeri Lampung, Jln. Soekarno-Hatta, Rajabasa Bandar Lampung Tel. 0721703995

\begin{abstract}
The effort to increase productivity of coffee plants in long dry season upland of Ultisol include application of Vesicular Arbuscular Mycorrhizae (VAM) on coffee plants, because its application only one time and its affect along a life time of coffee plant in the field. This study aims to determine the exact time and applications method of VAM on growth coffee seedlings. This study used $10 \mathrm{~g}$ $V A M / p o l y b a g$ or 800 spores as basic treatment. This study used randomized block design and experiment arranged in factorial $3 \times 5$ with three replications. The first factor was the time of VAM application: given at nursery seedlings $\left(W_{1}\right)$, given at transplanting $\left(W_{2}\right)$, and combine of given at nursery seedlings and transplanting $\left(W_{3}\right)$. The second factor was the applications method of VAM: without VAM inoculant $\left(C_{0}\right)$, VAM inoculant placed around the coffee seedling root up to a depth of $2 \mathrm{~cm}$ below root $\left(C_{1}\right)$, up to a depth of $4 \mathrm{~cm}$ below root $\left(C_{2}\right)$, up to a depth of $6 \mathrm{~cm}$ below root $\left(C_{3}\right)$, and VAM inoculant mixed with media planting $\left(C_{4}\right)$. All data were analyzed for variance. Data analysis followed by separation of means using LSD test with significance level of 5\%. The resulted showed that both time and applications method of VAM have affect on growth component and root infection rate. The best application time was double application, i.e. combine of given at nursery seedlings and transplanting, and the best applications method was VAM inoculant placed around the coffee seedling root up to a depth of $2 \mathrm{~cm}$ below root, both of them increased plant height, stem diameter, leaf amount, long of root, and root infection rate.
\end{abstract}

Keywords: Vesicular Arbuscular Mycorrhizae, seedlings, root infection

Diterima29-07 2014, disetujui: 22-08-2014

\section{PENDAHULUAN}

Penyebab menurunnya produksi kopi di Lampung salah satunya adalah usia tanaman kopi yang sudah tua, karena sudah melewati usia 20 tahun (Sumirat, 2013). Demikian pula, Puslitkoka (2013) menyatakan bahwa produktivitas tanaman kopi di Lampung telah menurun akibat banyaknya populasi tanaman kopi yang sudah tua, termasuk kurangnya perawatan lahan dan frekuensi pemupukan sehingga menyebabkan produktivitas tanaman kopi menjadi menurun. Di samping itu, petani masih menggunakan bibit tanaman bersifat tidak seragam, rentan terhadap 
serangan hama dan penyakit serta potensi produktivitasnya rendah. Oleh karena itu, peremajaan tanaman kopi tua harus mendapat perhatian disertai dengan budidaya tanaman yang optimal untuk memperoleh produksi kopi yang tinggi dengan mutu yang baik. Peningkatan mutu kopi dengan cara demikian akan meningkatkan devisa negara karena harganya yang tinggi di pasar dunia (Dinas Perkebunan Provinsi Lampung, 2012).

Usaha meningkatkan produktivitas tanaman kopi diawali dengan penggunaan bahan tanam unggul dan penggunaan teknologi unggul yang mampu meningkatkan pertumbuhan tanaman. Salah satu teknologi unggul tersebut adalah penerapan cendawan mikoriza arbuskula (CMA) pada tanaman kopi. Untuk mendapatkan simbiosis yang baik antara tanaman kopi dengan CMA, perlu dimulai dari aplikasi inokulan CMA pada pembibitan kopi, karena CMA dapat bersimbiosis dengan beberapa tanaman perkebunan, seperti, kopi, sawit (Widiastuti, dkk., 2005), karet, tebu (Basuki, 2013).

Aplikasi CMA pada pembibitan kopi diharapkan dapat meningkatkan pertumbuhan bibit kopi. Hal ini didasarkan atas beberapa hasil penelitian menunjukkan bahwa CMA meningkatkan pertumbuhan beberapa bibit tanaman. Hasil penelitian pada bibit jarak pagar menunjukkan bahwa inokulasi Glomus sp1. dan Glomus sp2. meningkatkan pertumbuhan tinggi, diameter, dan bobot kering bibit yang berumur tiga bulan berturut-turut dibandingkan dengan kontrol (Irianto, 2009).

Pertumbuhan dan perbanyakan CMA dilakukan melalui perkecambahan spora, akar terinfeksi dan hifa dalam tanah ketika mendapatkan medium pertumbuhan yang cocok. Saat perkecambahan dan pertumbuhan spora, akar terinfeksi dan hifa nampaknya tidak bersamaan, demikian pula tingkat kepadatan inokulan di sekitar akar berpengaruh terhadap infeksi akar, langkah awal terjadinya penetrasi hifa ke dalam akar, sehingga dalam percobaan ini telah diteliti pengaruh waktu dan cara aplikasi CMA pada bibit tanaman kopi. Penelitian ini bertujuan untuk menentukan waktu dan cara aplikasi CMA yang tepat untuk pertumbuhan bibit kopi.

\section{METODE}

Penelitian ini telah dilaksanakan di kebun praktik Politeknik Negeri Lampung, mulai awal September 2013 sampai April 2014. Bahan-bahan yang digunakan adalah biji kopirobusta, inokulan CMA, pestisida, dan pupuk Urea, SP-36, dan KCl. Alat-alat yang digunakan adalah cangkul, drum air, polibeg, meteran, timbangan, kawat, handsprayer, ember plastik, kamera digital, dan alat-alat tulis. Penelitian ini menggunakan mikoriza $10 \mathrm{~g} /$ polibeg atau 800 spora per polibeg sebagai perlakuan dasar. Penelitian ini menggunakan rancangan kelompok teracak sempurna (RKTS) dengan tiga ulangan dan percobaan disusun secara faktorial $3 \times 5$. Faktor pertama adalah waktu aplikasi mikoriza pada pembibitan, yaitu diaplikasi waktu pendederan biji $\left(\mathrm{W}_{1}\right)$, diaplikasi waktu pindah tanam $\left(\mathrm{W}_{2}\right)$, dan diaplikasi waktu pendederan biji dan pindah tanam atau aplikasi ganda $\left(\mathrm{W}_{3}\right)$. Faktor kedua adalah cara aplikasi mikoriza, yaitu tanpa inokulan CMA $\left(\mathrm{C}_{0}\right)$, inokulan CMA diletakkan di sekitar perakaran benih sampai kedalaman $2 \mathrm{~cm}$ di bawah akar $\left(\mathrm{C}_{1}\right)$, sampai kedalaman $4 \mathrm{~cm}$ di bawah akar $\left(\mathrm{C}_{2}\right)$, sampai kedalaman $6 \mathrm{~cm}$ di bawah akar $\left(\mathrm{C}_{3}\right)$, dan inokulan CMA dicampurkan ke media tanam $\left(\mathrm{C}_{4}\right)$. Seluruh data yang diperoleh dianalisis dengan sidik ragam. Analisis dilanjutkan dengan pemisahan nilai tengah menggunakan uji BNT dengan taraf nyata $5 \%$. 


\section{HASIL DAN PEMBAHASAN}

Hasil pengamatan menunjukkan bahwa waktu aplikasi dan cara aplikasi CMA berpengaruh nyata terhadap hampir semua variabel pengamatan yang diukur termasuk tingkat infeksi akar bibit kopi. Waktu aplikasi inokulan CMA yang lebih baik yaitu inokulasi ganda $\left(\mathrm{W}_{3}\right)$ yang diberikan saat pendederan biji kemudian diulangi lagi saat pindah tanam bibit, sedangkan aplikasi inokulan pada waktu pendederan biji $\left(\mathrm{W}_{1}\right)$ memberikan pengaruh yang kurang baik terhadap semua variabel pengamatan yang diukur. Bibit yang diberi inokulasi ganda secara nyata meningkatkan tinggi tanaman $(10,45 \%)$, diameter batang $(10,26 \%)$, jumlah daun $(4,89 \%)$, dan panjang akar $(4,23 \%)$, secara berturut-turut disajikan pada Gambar 1 dan 2, jika dibandingkan dengan bibit yang diberi inokulan CMA saat pendederan biji $\left(\mathrm{W}_{1}\right)$. Pada perlakuan waktu aplikasi, infeksi akar tertinggi (Gambar 1a) terdapat pada perlakuan inokulasi ganda, dan yang terkecil adalah perlakuan inokulasi saat pendederan biji $\left(\mathrm{W}_{1}\right)$.

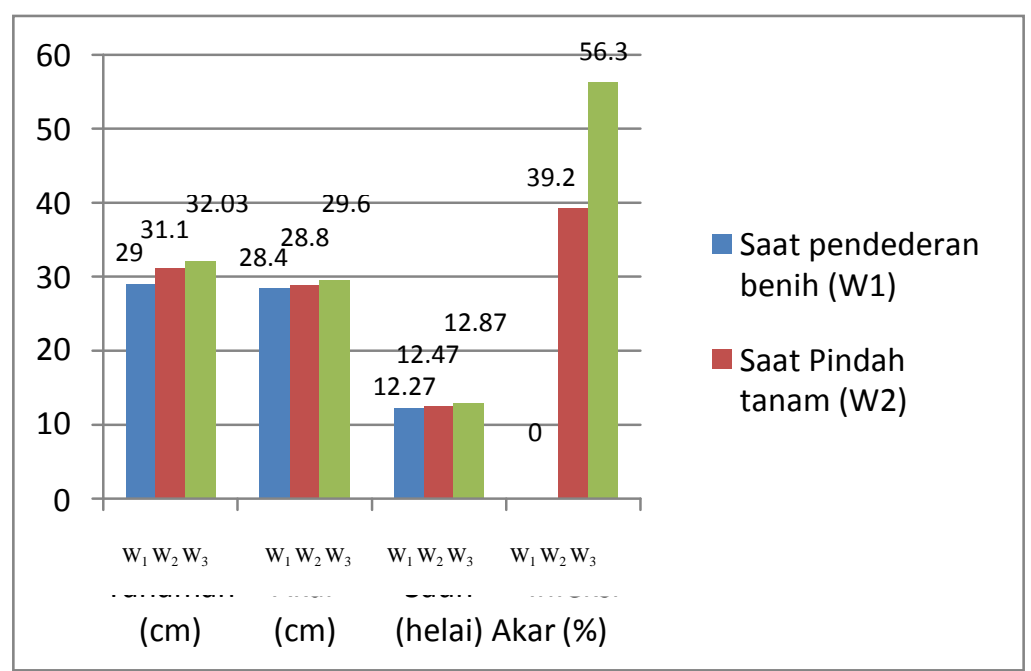

Gambar 1. Pengaruh waktu aplikasi CMA terhadap tinggi tanaman, panjang akar, jumlah daun, dan persen infeksi akar.

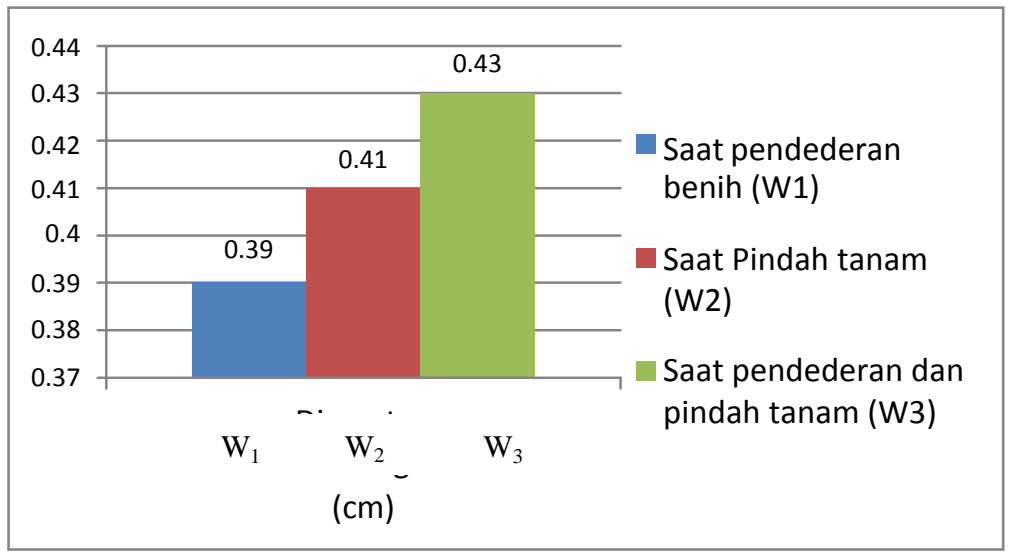

Gambar 2. Pengaruh waktu aplikasi CMA terhadap diameter batang.

Pada perlakuan cara aplikasi CMA, perlakuan yang memberikan nilai lebih tinggi untuk semua variabel pengamatan adalah yang diaplikasikan di sekitar perakaran sampai kedalaman $2 \mathrm{~cm}$ di bawah akar $\left(\mathrm{C}_{1}\right)$, sedangkan yang terendah adalah perlakuan tanpa inokulan CMA $\left(\mathrm{C}_{0}\right)$. Bibit 
Yonathan Parapasan dan Adryade Reshi Gusta: Waktu dan cara aplikasi Cendawan Mikoriza ...

yang diberi perlakuan cara aplikasi CMA di sekitar perakaran sampai kedalaman $2 \mathrm{~cm}$ di bawahnya $\left(\mathrm{C}_{1}\right)$ dapat meningkatkan tinggi tanaman (Gambar 3), jumlah daun (Gambar 3), panjang akar (Gambar 3), persen infeksi akar (Gambar 3), dan diameter batang (Gambar 4) secara berturut-turut lebih tinggi dibanding dengan perlakuan tanpa aplikasi CMA $\left(\mathrm{C}_{0}\right)$.

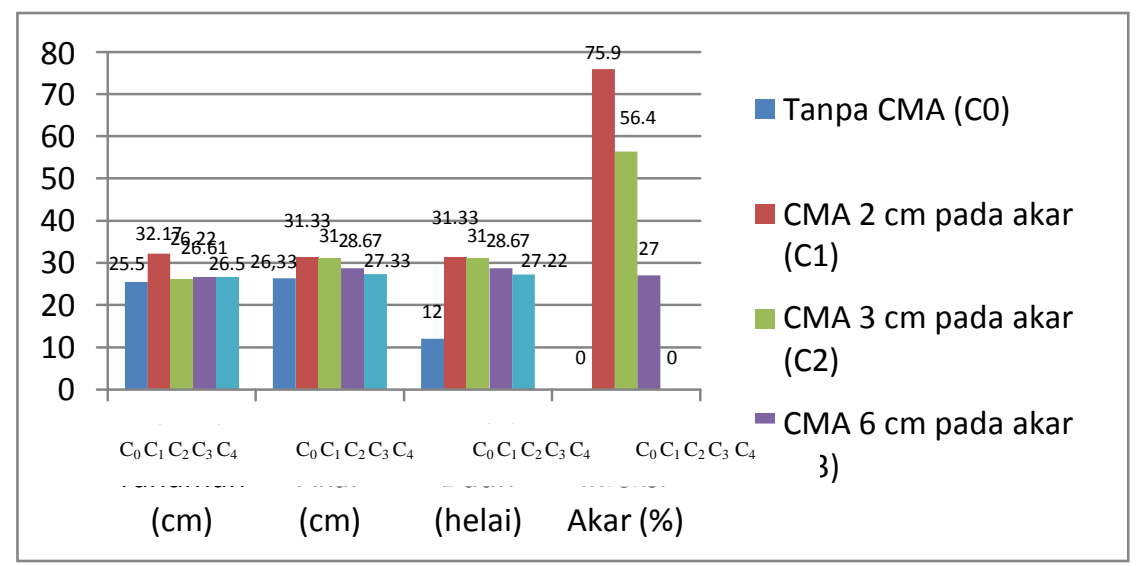

Gambar 3. Pengaruh cara aplikasi CMA terhadap tinggi tanaman, panjang akar, jumlah daun, dan persen infeksi akar.

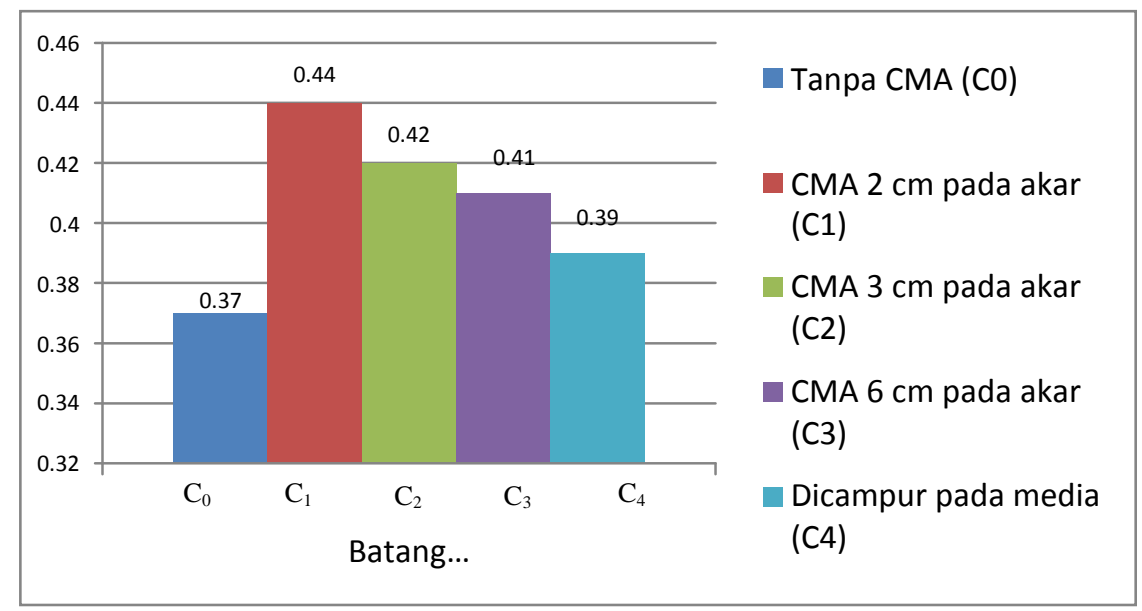

Gambar 4. Pengaruh cara aplikasi CMA terhadap diameter batang.

Data di atas menunjukkan bahwa pemberian CMA efektif dalam mengoptimalkan pertumbuhan bibit tanaman kopi. CMA yang diaplikasikan pada bibit kopi akan mengeluarkan hifa yang akan menginfeksi akar tanaman. Hifa yang keluar dari spora yang berkecambah akan mencari eksudat akar yang dikeluarkan oleh tanaman sebagai bahan makanan CMA untuk menembus akar. Hifa yang telah menembus akar akan berkembang di dalam dan di antara sel akar, kemudian hifa akan berubah sebagai tempat pertukaran unsur hara dengan fotosintat yang disebut arbuskula. Disamping itu, CMA di dalam sel akar akan memproduksi jaringan hifa eksternal yang berkembang seacar ekspansif berupa kolonisasi hifa yang tumbuh dan berkembang melalui bulubulu akar tanaman sehingga mampu memperluas bidang serapan dan meningkatkan penyerapan hara oleh tanaman, terutama fosfat (P). Hifa eksternal tersebut akan membantu mendekatkan unsur hara dari zona rhizosfer pada tanaman inang sehingga penyerapan hara lebih optimal dan pertumbuhan dan perkembangan tanaman menjadi lebih cepat (Talanca, 2010). Hasil penelitian serapan hara juga dilaporkan oleh Kabirun (2002), Hasanudin (2003), dan Musfal (2010), yaitu 


\section{Jurnal Penelitian Pertanian Terapan}

CMA dapat meningkatkan serapan nitrogen $(\mathrm{N})$ dan kalium (K). Pemberian CMA pada tanaman kacang-kacangan dapat meningkatkan serapan unsur mikro $\mathrm{Cu}$ dan $\mathrm{Zn}$.

Penyerapan air dan unsur hara yang cukup oleh tanaman menyebabkan pertumbuhan tanaman menjadi lebih baik, yang ditunjukkan dengan pertumbuhan tinggi tanaman yang optimal (Sastrahidayat dan Rochdjatun, 2011). CMA juga berperan dalam menstimulus pembentukan hormon-hormon pertumbuhan tanaman, seperti sitokinin dan auksin. Hormon sitokinin dan auksin ini berperan dalam pembelahan dan pemanjangan sel, sehingga menyebabkan peningkatan tinggi tanaman (Talanca, 2010). Pertumbuhan akar yang baik akibat inokulasi CMA dapat meningkatkan pertumbuhan tajuk melalui tinggi tanaman kopi, diameter batang, dan jumlah daun. Yildiz (2010) menyatakan bahwa pertumbuhan tajuk tanaman mentimun dan tomat yang diberi CMA lebih baik dibanding dengan tanaman yang tidak diberi CMA. Tanaman yang diberi CMA memiliki perakaran yang lebih baik, karena hifa yang berada di luar akar membantu penyerapan unsur hara terutama unsur $\mathrm{P}$ dan air yang dibutuhkan oleh tanaman untuk pertumbuhan.

Infeksi akar merupakan awal dimulainya simbiosis antara CMA dengan akar tanaman. Dalam penelitian ini, tingkat infeksi akar yang tergolong tinggi terdapat pada perlakuan aplikasi ganda CMA (diberikan saat pendederan biji dan pindah tanam bibit) yakni sekitar 56\%, inokulan CMA diberikan di sekitar perakaran sampai kedalaman $2 \mathrm{~cm}$ di bawah akar $(75,9 \%)$, dan inokulan diberikan di sekitar perakaran sampai kedalaman $4 \mathrm{~cm}$ di bawah akar (75,9\%). Hal ini didasarkan atas pernyataan Prihastuti, dkk. (2010) bahwa tingkat infeksi akar oleh mikoriza dikategorikan cukup tinggi jika mencapai nilai lebih tinggi dari 50\%, demikian juga Rini, dkk. (2014) mengemukakan bahwa simbiosis yang baik yang terjadi antara CMA dengan akar tanaman jika menunjukkan angka persen infeksi lebih dari 50\%.

Tingginya infeksi akar pada perlakuan aplikasi ganda (diberikan saat deder biji dan pindah tanam bibit) diduga akibat hifa yang melakukan penetrasi ke dalam akar lebih banyak, sehingga semakin meningkatkan pertumbuhan hifa di dalam jaringan sel akar, selanjutnya akan memperbanyak hifa eksternal yang berfungsi untuk memperbesar bidang serapan air dan unsur hara. Demikian juga halnya yang terjadi pada perlakuan C1 (inokulan diberikan sampai kedalaman $2 \mathrm{~cm}$ di bawah akar), karena kerapatan atau konsentrasi inokulan pada perlakuan itu lebih tinggi dibanding dengan perlakuan lainnya.

Tidak adanya infeksi akar baik pada waktu CMA hanya diberikan pada saat pendederan benih (W1) atau inokulan CMA dicampur dengan media tanam (C4), maupun tanpa inokulan CMA (C0) diduga karena kurangnya kerapatan inokulan di sekitar akar sehingga kontak langsung antara inokulan CMA dengan akar juga semakin berkurang. Akibatnya, penetrasi hifa ke dalam akar semakin terbatas sehingga tidak memberikan nilai terhadap infeksi akar. Dengan demikian, waktu aplikasi CMA yang lebih tepat adalah saat bibit mulai mengeluarkan akar, dan cara aplikasi yang lebih tepat adalah inokulan CMA diletakkan di sekitar perakaran bibit.

\section{KESIMPULAN}

Bibit yang diberi inokulasi ganda dapat meningkatkan tinggi tanaman, diameter batang, jumlah daun, panjang akar, dan persen infeksi akar jika dibandingkan dengan bibit yang diberi inokulan CMA saat pendederan biji. 
Yonathan Parapasan dan Adryade Reshi Gusta: Waktu dan cara aplikasi Cendawan Mikoriza ...

Bibit yang diberi perlakuan cara aplikasi CMA di sekitar perakaran sampai kedalaman 2 $\mathrm{cm}$ di bawah akar dapat meningkatkan tinggi tanaman, diameter batang, jumlah daun, panjang akar, dan persen infeksi akar.

\section{UCAPAN TERIMA KASIH}

Ucapan terima kasih disampaikan kepada Staf Dosen Jurusan Perkebunan Politeknik Negeri Lampung yang telah memberikan saran-saran perbaikan sehingga pelaksanaan dan pelaporan penelitian, sampai pada penyusunan artikel ilmiah ini dapat dilaksanakan.

\section{DAFTAR PUSTAKA}

Basuki. 2013. Pengaruh cendawan mikoriza arbuskula (CMA) terhadap karakteristik agronomi tanaman tebu sistem tanam bagal satu. Menara Perkebunan. 81(2): 50-54.

Dinas Perkebunan Provinsi Lampung. 2012. Statistik Perkebunan Indonesia 2003-2007. Bandar Lampung.

Irianto, R.S.B. 2009. Pengaruh Inokulasi Fungi Mikoriza Arbuskula terhadap Pertumbuhan Bibit Jarak Pagar Di Persemaian. Jurnal Penelitian Hutan dan Konservasi Alam. 6(2): 195-201.

Hasanudin. 2003. Peningkatan ketersediaan dan serapan N dan P serta hasil tanaman jagung melalui inokulasi mikoriza, azotobakter dan bahan organik pada Ultisol. Jurnal Ilmu Pertanian Indonesia. 5(2): 83-89.

Kabirun, S. 2002. Tanggap padi gogo terhadap inokulasi mikoriza arbuskula dan pemupukan fosfat di Entisol. Jurnal Ilmu Tanah dan Lingkungan. 3(2): 49-56.

Musfal. 2010. Potensi Cendawan Mikoriza Arbuskula Untuk Meningkatkan Hasil Tanaman Jagung. Jurnal Litbang Pertanian. 29(4):154-158.

Prihastuti, Sudaryono, dan E. Handayanto. 2010. Keanekaragaman jenis mikoriza vesikula arbuskula dan potensinya dalam pengelolaan kesuburan tanah Ultisol. Seminar Nasional Biologi, Fakultas Biologi UGM, Yogyakarta 24-25 September 2010.

Puslitkoka. 2013. Produktivitas tanaman kopi di Lampung. http://bisnis.news.viva.co.id/news/read/ 417948-produktivitas-kopi-ri-terancam-menurun. Diakses Tanggal 9 Agustus 2013.

Rini, M.V., Ari D.J., dan Sugiatno. 2014. Pengaruh lima jenis fungi mikoriza arbuskular dan dosis pupuk anorganik pada pertumbuhan bibit kopi robusta (Coffe canephora Pierre). Seminar Nasional Polinela, Bandar Lampung 24 Mei 2014.

Sastrahidayat, I. R. 2011. Rekayasa Pupuk Hayati Mikoriza Dalam Meningkatkan Produksi Pertanian. Universitas Brawijaya Press, Malang.

Sumirat, U. 2013. Produktivitas Kopi RI Terancam Menurun. http://bisnis.news.viva co.id/news/read/417948-produktivitas-kopi-ri-terancam-menurun. Diakses Tanggal 9 Agustus 2013. 


\section{Jurnal Penelitian Pertanian Terapan}

Talanca, H. 2010. Status Cendawan Mikoriza Vesikular Arbuskular (MVA) pada Tanaman. Prosiding Pekan Serealia Nasional. Balai Penelitian Tanaman Serealia, Sulawesi Selatan.

Widiastuti, H., S. Nampiah, K.D. Latifah, H.G. Didiek, S. Sally, dan G. Edi. 2005. Penggunaan spora cendawan mikoriza arbuskula sebagai inokulum untuk meningkatkan pertumbuhan dan serapan hara bibit kelapa sawit. Menara Perkebunan. 73(1): 26-34.

Yildiz, A. 2010. A native Glomus sp. from field in Aydin province and effects of native and commercial mycorrhizal fungi inoculants on the growth of some vegetables. Turk $J$. Biology, 34: 447-452. 